\title{
LUT
}

University

\section{Recognizing Life Cycle Benefits of Real Time Fatigue Monitoring for Ecosystems}

Rissanen Matti, Metso Lasse, Sinkkonen Tiina, Kärri Timo

This is a Post-print

version of a publication

published by Springer

in Ball, A., Gelman, L., Rao, B. (eds) Advances in Asset Management and Condition Monitoring. Smart Innovation, Systems and Technologies, vol 166

DOI: 10.1007/978-3-030-57745-2_35

Copyright of the original publication: (c) Springer Nature

Please cite the publication as follows:

Rissanen, M., Metso, L., Sinkkonen, T., Kärri, T. (2020). Recognizing Life Cycle Benefits of Real Time Fatigue Monitoring for Ecosystems. In: Ball A., Gelman L., Rao B. (eds) Advances in Asset Management and Condition Monitoring. Smart Innovation, Systems and Technologies, vol 166. pp. 417-428. DOI: 10.1007/978-3-030-57745-2_35

This is a parallel published version of an original publication. This version can differ from the original published article. 


\title{
Recognizing Life Cycle Benefits of Real Time Fatigue Monitoring for Ecosystems
}

\author{
Matti Rissanen ${ }^{1 *[0000-0002-7878-8235]}$, Lasse Metso ${ }^{1[0000-0001-5670-8524]}$, Tiina Sinkkonen ${ }^{1[0000-}$ \\ 0003-3821-5800] and Timo Kärri ${ }^{10000-0002-6659-1419]}$ \\ ${ }^{1}$ LUT University, Industrial Engineering and Management, Lappeenranta, Finland \\ matti.rissanendut.fi
}

\begin{abstract}
Real time fatigue monitoring creates various benefits in multiple categories appearing at different points of the item's life cycle. One monitoring and analytics service can be beneficial for a large set of actors, an ecosystem. An ecosystem consists of actors that work towards a common goal, a focal value proposition. In our case, this focal value proposition is management of an item's life cycle in real time. The purpose of this paper is to recognize benefits related to real time monitoring and analytics of fatigue in welded steel structures and to recognize a set of actors that can form a new ecosystem for creating these benefits. The benefits are recognized in interviews with practitioners who observe the lack of reliable analytics in the remaining life of the items they design, manufacture, maintain or operate. The interviewees represent different parts of an item's life cycle and during the interviews are asked to recognize and rank benefits and to form a potential new ecosystem from their perspective. The recognized benefits are for example in improving communication between product design and production, improved maintenance scheduling, prolonged production time, correctly timed replacement investment decisions. The interviewees do not form a unified opinion of a new ecosystem but rather we recognize two categories of companies that form the basis for future research in the subject. The interviewees agree that real time monitoring holds huge potential for benefits but is not yet adopted in large scale in practice.
\end{abstract}

Keywords: Fatigue monitoring $\cdot$ Real time $\cdot$ End-of-life $\cdot$ Steel structures Ecosystem $\cdot$ Life cycle

\section{Introduction}

Welded steel structures are designed to sustain certain amount of fatigue in certain conditions but when the conditions are not default but rather varying, e.g. weather or operational effects, the life of the whole item does not follow its design. This causes problems when trying to operate the item affected by fatigue damage optimally. For example, based on our interviews, maintenance is scheduled more often than necessary to prevent failures and the item is replaced before the real end of its life because reliable information on the remaining life is not available. 
Refamo is a research project of a real time fatigue monitoring and analytics system for determining the remaining life of a welded steel structure. The interviews conducted in Refamo discussed the benefits of such a system in bigger scope than the specific system can be applied to currently. The interviews provide views on benefits of real time fatigue monitoring in a general level and at the same time help develop the system under research further. In this paper, Refamo refers to real time fatigue monitoring.

By applying Refamo to the item facing varying conditions through natural or human causes, the real end-of-life point can be determined and momentary fatigue to the item at any time during monitoring can be determined and analysed. For example, for heavy equipment used in mining, one of the main issues is fatigue caused by natural causes [1] and Refamo can help manage it. We use the term 'item' throughout this paper to discuss the different equipment, machines and structures that were subjects of our interviews. [2, p. 12] defines 'item' as 'part, component, device, subsystem, functional unit, equipment or system that can be individually described and considered".

An ecosystem in a business context is a concept that considers companies and their relations that are not limited to any one industry [3, 4]. The actors within one interact with each other to realize a common goal, a focal value proposition [3]. When we consider an ecosystem that forms around Refamo, we can have various actors operating in different points of an item's life cycle. For example, an ecosystem can consists of the manufacturers of an item (even if they compete with each other), a monitoring and analytics provider, an operator of the item, a maintenance partner, a research institute studying something related to the item, regulators making regulations based on confirmed data, professional organisations, and so on. This paper discusses the benefits of using Refamo throughout the life cycle of an item and the new ecosystem to be created. In this study, we look to answer two research questions through interviews with practitioners:

RQ1: What are the main benefits of using Refamo?

RQ2: Which set of actors can form a new Refamo ecosystem?

\section{$2 \quad$ Literature review}

Condition-based maintenance (CBM) has been used in automated manufacturing in which condition monitoring is understood to contain data acquisition, processing, analysis, interpretation and extracting information [5]. Vibration analysis has been done with rotating parts in an engine because vibration is one element to cause minor or serious problems to a machine [6].

Structural health monitoring (SHM) can be seen as a strategy for damage identification in aerospace, civil and mechanical engineering infrastructure. SHM is based on periodical measurements [7]. SHM in real time can reduce inspection and repair costs. The other advance in SHM is lifetime monitoring of any construction projects. For example, Jindo Bridge was a collaborative project between participants from US, South Korea and Japan to real time monitoring. It was the largest project to monitor a bridge with wireless sensors. A lot of data collected and analysed in the project. [8] 
[9] examined the implementing of long-term SHM in large-scale bridges. Bridges are unshielded from environmental conditions - humidity, wind, solar-radiation and temperature as well as operational effects - traffic and other loads. SHM can give a new way to inspect and monitor the safety of bridges.

Condition monitoring systems have been used in wind turbines and helicopter gearboxes online measurements [10]. Condition monitoring is needed in wind turbines because those are unmanned and located far away from maintenance service providers. Wind turbines are under unkind weather conditions, e.g. wind, heat, cold, lightning, rain, ice and snow. Monitoring the condition of wind turbines preventative maintenance can be adopted instead of corrective maintenance [11]. Many operational fields (e.g. ports) operated with heavy equipment are becoming staffed with less people and therefore there is a need to monitor the equipment and their use in real time [12]. The monitoring and analytics can help in improving the operation of the fields and provide data for operational planning [13]. Successful preventive maintenance operations reduce the unscheduled downtime of an item and therefore can improve the productivity during its life cycle [14]. [15] note that deterioration and failures in items that do not wear evenly during their use can cause high costs or safety hazards. Excessive maintenance can, however, eliminate the cost benefits [16].

[17] consider condition monitoring, life extension, repair versus replace, and optimized life cycle management the most important issues of item life cycle management. Said issues are also of the essence in our research as real time fatigue monitoring in some cases aims to extend production time of an item, provides accurate information on when the items end-of-life is, and allows optimal life cycle management through flexible scheduling of maintenance operations. In some instances, the fatigue on items is highly dependent on how it is operated and the benefits from monitoring the item extends further than maintenance management.

\section{Research Design}

This study is based on data from seven qualitative semi-structured interviews. For structuring the interviews, we adopted the localist position (see [18]) since we are looking into a complex organizational phenomenon of organizations forming an ecosystem to work towards a common goal with a real time fatigue monitoring and analysis technology and tool. Semi-structured interview consists of prepared questioning within predetermined themes [18].

The interviewees were chosen based on initial market analysis on national level that recognized these companies as potential benefiters of Refamo and key actors in a new Refamo ecosystem. The companies were also chosen to represent a wide scale of industries and positions in an item's life cycle. The interviewees' titles and the fields of business of their companies are presented in Table 1 and their position in item's life cycle is presented in Figure 1. The companies are encoded with letters from A to $G$ and in further sections of this paper the interviews are referred to with the respective company letter. Company $\mathrm{G}$ gave us two interviewees and many others mentioned that the questions we sent them beforehand were discussed by a group of people to give us 
wider perspective from the interviewed company rather than just one view. The interviews were conducted by a team of three university researchers - two concentrated on the benefits and ecosystem of Refamo, one on the technical perspective and expertise in welded steel structures. With this kind of team we could acknowledge the different backgrounds of interviewees by being able to contribute to the discussions raised by our interviewees.

Table 1. Interviewees and their fields of business.

\begin{tabular}{l|c|l} 
Field of business & Company & Title of interviewee \\
\hline Construction engineering & $\mathrm{A}$ & Senior structural expert \\
\hline Maintenance and engineering services & $\mathrm{B}$ & Maintenance manager \\
\hline Power plant operation & $\mathrm{C}$ & Investment portfolio manager \\
\hline Civil engineering & $\mathrm{D}$ & Bridge specialist \\
\hline Heavy equipment production and services & $\mathrm{E}$ & Test engineer \\
\hline Heavy equipment production and services & $\mathrm{F}$ & Research and development manager \\
\hline Power plant operation & $\mathrm{G}$ & Managing director \\
\hline Power plant operation & $\mathrm{G}$ & Project manager \\
\hline $\begin{array}{c}\text { Concept and } \\
\text { definition }\end{array}$
\end{tabular}

Fig. 1. Life cycle of an item and involvement of interviewed companies during it. [19]

Our interview consisted of four themes: product, data, value, and business model. Each theme formed around 2-4 pre-determined questions. The interview themes and questions can be found in Appendix 1. In addition, two surveys were conducted during the interviews. Surveys are used to gather information systematically in a quantitative form [20]. Our surveys were used at the end of value and business model themes to summarize the otherwise qualitative interview and potentially highlight important points that went unheeded. The first survey used the Likert-type scale to rank benefits relevant in the opinion of the interviewee. In the second survey, the interviewees created their own Refamo ecosystem by placing potential stakeholders in a circle where the scale was from one to five - one meaning little relevance and five high relevance within the ecosystem. The mapping of the ecosystem was done in similar manner as in research by [21]. The interviewee could also leave pre-determined potential stakeholders out of the circle or add their own ones.

\section{$4 \quad$ Results}

\subsection{Benefits from Using Refamo}

The main results in regards to benefits recognized from interviews are gathered here from each interview. Table 2 summarizes the results of the first survey with the most important benefits highlighted in colour in the case of company preferring some 5 rated benefits over others. If the company found all 5's as important, they are all coloured. 
A considers that they are not a potential user of Refamo since the items they design have to be designed in a way that they last in any conditions the designed amount of lifetime. They see their field of business as so conservative that even when there are benefits to using Refamo but the value might not be great enough for Refamo to be used. However, the benefits from using Refamo in large items with massive amount of welded structures could come from monitoring critical components and then the interested party would be the supplier of said components. Another benefit comes from automating some scheduled manual measurement operations. Instead of analysing the end-of-life point, the conservative industry could be interested in an analysis of how the item is not failing, and how some standardized scheduled measurements could be made automatic and safer.

B emphasizes the role suppliers of items in using Refamo in concept, and design and development phases of item's life cycle. In process industry, the biggest benefit and financial value from real time monitoring comes through reduced unexpected and planned shutdown time.

$\mathrm{C}$ noted that in process industry fatigue might not be the biggest issue since the loads often are kept as stable as possible. However, they have process items that endure varying loads where Refamo would be beneficial. These items are not the most important ones for $\mathrm{C}$ and therefore the financial value to be gained is unclear. In a bigger picture, some items, e.g. steam boilers, are very critical and the company attempts to calculate and simulate the remaining life of these critical items. A failure of such critical item would cause huge costs as downtime. Real time monitoring is something the company has been looking to improve on since there is also interest in using controlled overload to produce more when market demand is higher. Currently, the take on overload on some occasions according to interviewee is: "Now we will make money - the machine can take it.' Sometimes they last, sometimes they do not. It (the decision of overloading) is not based on any data."

Table 2. Survey on benefits of Refamo.

\begin{tabular}{|c|c|c|c|c|c|c|c|c|c|}
\hline & A & B & $\mathrm{C}$ & $\mathrm{D}$ & $\mathrm{E}$ & $\mathrm{F}$ & G & Avg & Mode \\
\hline \multicolumn{10}{|l|}{ Concept, design and development } \\
\hline Load and fatigue information for research and development & 5 & 5 & 5 & 2 & 5 & 5 & 3 & 4,3 & 5 \\
\hline Data storaging and later analyses & 5 & 4 & 4 & 2 & 5 & 5 & 5 & 4,3 & 5 \\
\hline Development of design methods and practices & & & & & 5 & 2 & & & \\
\hline \multicolumn{10}{|l|}{ Production } \\
\hline Estimating effects of production quality to item health & 1 & 5 & 4 & 2 & 5 & 4 & 3 & 3,4 & $4 ; 5$ \\
\hline \multicolumn{10}{|l|}{ Installation, operation and maintenance } \\
\hline Maintenance planning and execution & 3 & 4 & 5 & 5 & 4 & 5 & 4 & 4,3 & $4 ; 5$ \\
\hline Monitoring of momentary fatigue & 3 & 5 & 5 & 2 & 5 & 4 & 4 & 4,0 & 5 \\
\hline Real time monitoring of remaining life of an item & 3 & 5 & 5 & 5 & 5 & 2 & 4 & 4,1 & 5 \\
\hline Automated actions in regards of item health & 3 & 4 & 2 & 5 & 4 & 2 & 5 & 3,6 & - \\
\hline Sporadic measurement and analytics services & 3 & 2 & 2 & 4 & 2 & 4 & 5 & 3,1 & 2 \\
\hline Risk management & 3 & 4 & 5 & 4 & 4 & 2 & 5 & 3,9 & 4 \\
\hline Work safety & 3 & 5 & 4 & 2 & 2 & 2 & 5 & 3,3 & 2 \\
\hline Monitoring the user of a machine & & & & & 5 & 5 & & & \\
\hline Training of optimal use of a machine & & & & & 5 & 2 & & & \\
\hline Verifying claims for compensation & & & & & 4 & 4 & & & \\
\hline \multicolumn{10}{|l|}{ Disposal } \\
\hline \multirow{2}{*}{$\begin{array}{l}\text { Forecasting and optimising the remaining life of an item } \\
\text { Investment decision making }\end{array}$} & 5 & 4 & 5 & 5 & 5 & 4 & 4 & 4,6 & 5 \\
\hline & 3 & 5 & 5 & 5 & 4 & 2 & 4 & 4,0 & 5 \\
\hline
\end{tabular}

D noted the same as A, that the items are designed conservatively to last their whole lifetime without further monitoring, in D's case for a hundred years. However, the loads 
have increased during the life cycle of current items maintained by $\mathrm{D}$ and the loads are expected to increase in future. This means that the items are unlikely to last as long as designed and in some cases monitoring is already applied to failing items. D considers the same as A that the interest towards Refamo could be more among the companies manufacturing the items and it is difficult to see who would gain value from Refamo and therefore be willing to pay for it.

$\mathrm{E}$ involved in large parts of the item's life cycle and producing a heavy equipment directly to end customers sees the benefits from Refamo in two broad categories: benefits in the design and production of the item and benefits in monitoring the end users of items that are also maintained by company $\mathrm{E}$. A big issue for $\mathrm{E}$ is that tight competition drives the $R \& D$ processes to go through faster and time spent on testing is reduced. Therefore, all monitoring and analytics, including Refamo, that could improve the design process with reduced time spent on testing is highly beneficial. The benefits from the end user category come through improved training and knowledge of items along end users. Better use leads to less maintenance from E's side.

$\mathrm{F}$ does not do measuring themselves and mainly does the design and development of their items with established data and methods. Refamo would provide benefits in design through more optimized structures but the interviewee is sceptical if it would be cost-effective. A clear benefit would come through end user training and "forcing the end user to use the machine correctly". F manufactures in a smaller scale same heavy equipment as $\mathrm{E}$ and it can be recognized in the interview. Both emphasize the end user perspective and that is why for these interviewees it was included in the first survey.

$\mathrm{G}$ is a small service company involved in the installation, operation and disposal of items and their perspective in the interview was on how to benefit the owner of the items they operate. The main benefit from Refamo would be to reliably prove that the items life cycle is longer than designed and therefore would prolong the production time of items. G operates a fleet that is designed for twenty years of production time but they have a gut feeling that the production time could be much longer. However, they do not currently have a reliable data to prove it and Refamo could be beneficial in that regards.

On average, all the benefits surveyed are seen as beneficial by our interviewees (average over 3,0). The ones that have a mode answer of 5 are the most important across the board and can be found in all parts of the item's life cycle. Different interviewees emphasize different parts of the life cycle and for future research they have to be grouped to be fully comparable and the results to be generalizable.

\subsection{The New Refamo Ecosystem}

The second survey conducted during the interviews asked the interviewees to consider Refamo as a focal value proposition (see [3]) in a new ecosystem. Interviewees placed stakeholders they deemed relevant to form the ecosystem and the results are summarized in Table 3. Other suppliers included multiple company specific stakeholders and is presented as one. For companies B, F and G, Other suppliers is an average of two answers. Five stakeholders that were only considered relevant by one or two interviewees are not included in the summary. 
Table 3. Survey on potential stakeholders in a new Refamo ecosystem.

\begin{tabular}{l|cccccccc} 
& $\mathrm{A}$ & $\mathrm{B}$ & $\mathrm{C}$ & $\mathrm{D}$ & $\mathrm{E}$ & $\mathrm{F}$ & $\mathrm{G}$ & Var \\
\hline Company represented by interviewee & 2 & 5 & 5 & 5 & 5 & 5 & 4 & 1,10 \\
Interviewee's customers & 5 & 5 & 3 & & 5 & 4 & 4 & 0,56 \\
Competitors & 2 & 1 & 2 & & 1 & 2 & & 0,24 \\
Maintenance service provider & 5 & & & 4 & 1 & & 3 & 2,19 \\
Other monitoring and analytics providers & 2 & & 2 & 3 & 4 & 3 & 4 & 0,67 \\
Steel suppliers & 1 & 3 & 1 & 2 & 4 & 1 & 2 & 1,14 \\
Other suppliers & 5 & 2,5 & 2 & 2 & & 3,5 & 3 & 1.08 \\
End user & 1 & & & 1 & 4 & 4 & & 2,25 \\
Refamo company & 5 & & 5 & 4 & 1 & 2 & 5 & 2,56 \\
Refamo's other customers & 2 & & 1 & & 4 & 2 & 2 & 1,47 \\
University & 5 & 5 & 3 & 3 & 4 & 2 & 3 & 1,10
\end{tabular}

Variances calculated for the answers show that the only consensus about the new ecosystem is that there is no need to involve the competitors in a central role even if there could be benefits through faster development of the service. From the interviewed companies, only A did not consider themselves a potential user of Refamo, the rest placed themselves in the very center of the ecosystem (5) with the exception of company $\mathrm{G}$ placing themselves at 4 . B, C, E and F offer maintenance services themselves so they did not include other maintenance service providers in the ecosystem creating and sharing benefits of Refamo. In general, the suppliers of interviewees were not seen important in the ecosystem - with some exceptions in A, E and F - but rather the customers of interviewees were considered very important. For $\mathrm{E}$ and $\mathrm{F}$ the customers include the end users of their items. The role of university and research results in regards to Refamo in the ecosystem varies depending on the interviewees personal background. For example, A has a long research career before their current position and $\mathrm{B}$ and $\mathrm{E}$ have collaborated with university in research projects. Without $A$, the answers from other companies vary less with some stakeholders but still, it is difficult to form one unified ecosystem. However, combining the surveys and interview data, we can form two categories of companies (B, C, D, G and E, F) for future research purposes.

The main result from the second survey is the position of a Refamo service provider. $\mathrm{E}$ and $\mathrm{F}$ manufacture items that are used by their customer and have strong research and development departments within their organizations. They are very interested in using the technology but would rather produce the service themselves to gain competitive advantage. The rest of the interviewees would use Refamo in items that are used to produce the offering for their customers. They would not directly gain competitive advantage with Refamo but potentially gain value in other ways. B did not place Refamo company in the ecosystem as they did not want to take a stand on the procurement of Refamo.

\section{$5 \quad$ Discussion and Conclusions}

The goal of this study was to get a wide understanding about possible benefits created by Refamo and the views on the sets of actors to form an ecosystem around the value proposition. The interviews were approached as a source of good qualitative data with two surveys to summarize the discussions and provide part of the results in quantitative form. Interviewee A did not consider themselves in central position within the Refamo ecosystem whereas all other interviewees did. As can be seen in Figure 1, all 
but A are involved in the operation and maintenance phase of item's lifecycle. E and F are involved mainly by providing maintenance services to the machinery they have manufactured, thus they are shown to participate only halfway within the phase.

The companies that see themselves in central role within the ecosystem can be placed in two categories. The first category is companies B, C, D and G, who emphasize the operation and maintenance and disposal phases of the item's lifecycle where Refamo would be applied. They are open to getting Refamo services from an external service provider and are not seeking competitive advantage through Refamo but rather seek to reduce maintenance costs, costs related to lost production and increase the production time of their items. The most important benefits discussed with these companies were delaying new or re-investments, reducing production facility downtime due to both scheduled and unscheduled maintenance operations, and more accurate maintenance planning and organisation.

The second category is formed by companies E and F. They have monitoring and analytics capabilities within their organisation due to them producing high technology heavy machinery. They are engaged in a very competitive market and while they are clearly looking to gain competitive advantage by using Refamo, they would rather provide the service themselves to prevent competitors from gaining access to the benefits of Refamo. The most important benefits within this category were the feedback loop between product design and production, real usage data in real time for product design, usage data from end users, and optimisation of structures to for example make them lighter. The new ecosystems for each category are presented in Figure 2. The stakeholders scored as 3 or better on average are positioned in the average position for each category.
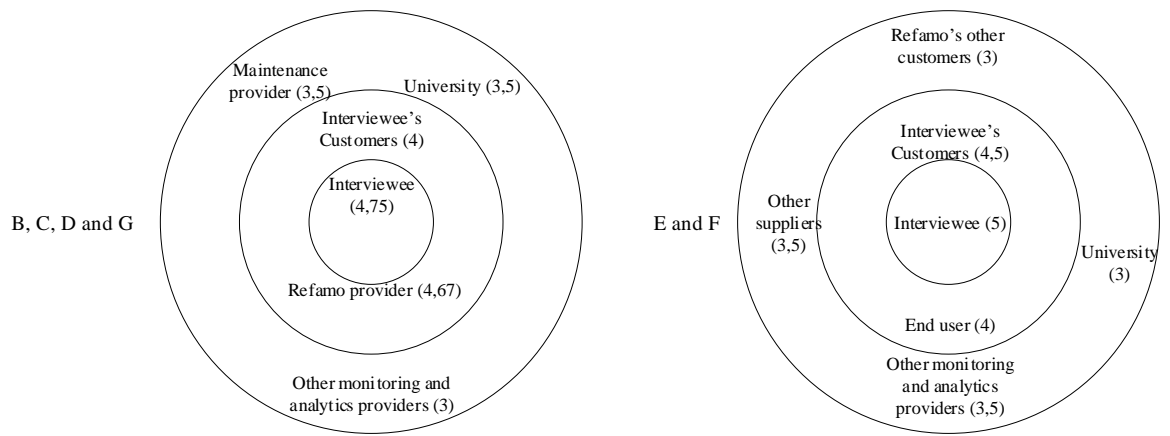

Fig. 2. New Refamo ecosystems for each category.

When we consider the benefits within the life cycle of an item, we notice that both recognized categories of companies aim to prolong the operation and maintenance phase through the benefits and the second category looks to also shorten the first three phases of the lifecycle. This is expected since all interviewed companies, with the exception of A, create increasing amount of their revenue in the operation and maintenance phase. The most potential benefits within the Refamo ecosystem are the ones positioned in design and development, production, and operation and maintenance 
phases within the life cycle. The benefits positioned in other phases cannot be overlooked but based on our interviews; benefits in aforementioned phases are the potential ones. The set of actors to form an ecosystem to realize the value proposition of Refamo differs in the two categories of companies formed based on the interviews. In most answers, the key actors include the company of the interviewee, their customers, a supplier, company providing Refamo as a service, and university.

\section{$6 \quad$ Limitations and Further Research}

\subsection{Limitations}

The interviewed companies did not currently have methods to accurately determine the remaining life of their items. The use of real time monitoring and analytics was very low as well. In general, they were very interested in the proposed system and could come up with benefits associated with it but since they have no experience from using such systems, there undoubtedly are still undiscovered benefits involved in using Refamo. Many of the interviewees pointed out some of their stakeholders that could in their opinion be even better ones to interview. In the scale of Refamo research project, the number of interviews were not increased from the initially planned ones. The industries our interviewees are part of differ very much. Some are very conservative, some in rapid growth and some very competitive. The same recognized benefit could create value in different ways depending on the company it is applied in, and for some companies it could be difficult to create any value even if the benefit is very clear.

\subsection{Further Research}

The scope of this paper was to identify the potential benefits of using Refamo and recognizing the set of actors to form a new value creating Refamo ecosystem. The value created within the ecosystem considers the costs and risks associated in achieving the identified benefits. The value creation of using Refamo in an ecosystem is to be modelled in further research. It is also necessary to study how the created value is distributed between the actors of the Refamo ecosystem. The value created in an ecosystem should be distributed and used to improve the ecosystem, not just one key actor.

\section{References}

1. Barnes, N., Joseph, T., Mendez, P. F.: Issues Associated with Welding and Surfacing of Large Mobile Mining Equipment for Use in Oil Sands Applications. Science and Technology of Welding and Joining 20(6), 483-493 (2015).

2. Finnish Standards Association SFS: Maintenance. Maintenance terminology. SFS-EN 13306:2017 (2017).

3. Adner, R.: Ecosystem as Structure: An Actionable Construct for Strategy. Journal of Management 43(1), 39-59 (2017).

4. Moore, J. F.: The Death of Competition: Leadership and Strategy in the Age of Business Ecosystems. Harper Business, New York (1996). 
5. Campos, J.: Development in the Application of ICT in Condition Monitoring and Maintenance. Computers in Industry 60(1), 1-20 (2009).

6. Goyal, D., Pabla, B.S.: The Vibration Monitoring Methods and Signal Processing Techniques for Structural Health Monitoring: a Review. Archives of Computational Methods in Engineering 23(4), 585-594 (2016).

7. Farrar, C.R., Worden, K.: An Introduction to Structural Health Monitoring. Philosophical Transactions of the Royal Society A: Mathematical, Physical and Engineering Sciences 365(1851), 303-315 (2006).

8. Spencer, B.F., Cho, S.: Wireless Smart Sensor Technology for Monitoring Civil Infrastructure: Technological Developments and Full-scale Applications. In: Proceedings of the World Congress on Advances in Structural Engineering and Mechanics, pp. 4277-4304. Seoul (2011).

9. Ko, J.M., Ni, Y.Q.: Technology Developments in Structural Health Monitoring of Largescale Bridges. Engineering Structures 27(12), 1715-1725 (2005).

10. Hyers, R.W., McGowan, J.G., Sullivan, K.L., Manwell, J.F., Syrett, B.C.: Condition Monitoring and Prognosis of Utility Scale Wind Turbines. Energy Materials 1(3), 187-203 (2006).

11. Tchakoua, P., Wamkeue, R., Ouhrouche, M., Slaoui-Hasnaoui, F., Tameghe, T., Ekemb, G.: Wind Turbine Condition Monitoring: State-of-the-art Review, New Trends, and Future Challenges. Energies 7(4), 2595-2630 (2014).

12. Mi, C., He, X., Liu, H., Huang, Y., Mi, W.: Research on a Fast Human-Detection Algorithm for Unmanned Surveillance Area in Bulk Ports. Mathematical Problems in Engineering, 117 (2014).

13. Azar, E. R., Dickinson, S., McCabe, B.: Server-Customer Interaction Tracker: Computer Vision-Based System to Estimate Dirt-Loading Cycles. Journal of Construction Engineering and Management 139(7), 785-794 (2013).

14. Takata, S., Kirnura, F., van Houten, F.J.A.M., Westkamper, E., Shpitalni, M., Ceglarek, D., Lee, J.: Maintenance: Changing Role in Life Cycle Management. CIRP Annals - Manufacturing Technology 53(2), 643-655 (2004).

15. Grall, A., Bérenguer, C., Dieulle, L.: A Condition-based Maintenance Policy for Stochastically Deteriorating Systems. Reliability Engineering and System Safety 76(2), 167-180 (2002).

16. Yang, Z.M., Djurdjanovic, D., Ni, J.: Maintenance Scheduling in Manufacturing Systems Based on Predicted Machine Degradation. Journal of Intelligent Manufacturing 19(1), 8798 (2008)

17. Brown, R.E., Willis, H.L.: The Economics of Aging Infrastructure. IEEE Power and Energy Magazine 4(3), 36-43 (2006).

18. Qu, S.Q., Dumay, J.: The Qualitative Research Interview. Qualitative Research in Accounting \& Management 8(3), 238-264 (2011).

19. International Electrotechnical Commission IEC: Dependability management - Part 3-3: Application guide - Life cycle costing. 60300-3-3:2004 (2004).

20. Groves, R.M., Fowler, Jr., F.J., Couper, M.P., Lepkowski, J.M., Singer, E., Tourangeau, R.: Survey Methodology. 2nd edn. John Wiley \& Sons, Hoboken NJ (2011).

21. Jaspersen, L. J., Stein, C.: Beyond the Matrix: Visual Methods for Qualitative Network Research. British Journal of Management, 1-16 (2019) 


\section{Appendix 1. Interview themes and questions}

\section{Theme 1: Product}

- Is managing the fatigue damage on a steel structure interesting?

- How real time fatigue monitoring ( $\mathrm{ReFaMo})$ could be used in items designed, manufactured and/or operated by your company?

- What other items could ReFaMo be used with?

\section{Theme 2: Data}

- What data do you gather related to steel structures?

- What new measurement data ReFaMo would bring to you and how is it compatible with your current measurement and analysis system?

- How should data ownership be considered within a service like ReFaMo?

\section{Theme 3: Value}

- What benefits and value ReFaMo could hold?

- What kind of decision making situations ReFaMo could be used in?

- How would you financially measure the value of ReFaMo?

\section{Theme 4: Business model}

- Do you buy measurement and analysis services from external providers?

- How do you see the role of measurement and analysis services in future (in 2025) in your items and in your industry? 